\title{
Argumentative Thinking: An Introduction to the Special Issue on Psychology and Argumentation
}

\author{
LANCE J. RIPS
}

Weinberg College of Arts and Sciences

Department of Psychology

Swift Hall 102

2029 Sheridan Road

Evanston, IL 60208-2710

U.S.A.

rips@northwestern.edu

\begin{abstract}
This special issue of Informal Logic brings together a number of traditions from the psychology and philosophy of argument. Psychologists' interest in argument typically arises in understanding how individuals form and change their beliefs. Thus, theories of argument can serve as models of the structure of justifications for belief, as methods of diagnosing errors in beliefs, and as prototypes for learning. The articles in this issue illustrate all three of these connections.
\end{abstract}

Resume: Ce numéro spécial d'Informal Logic rassemble quelques traditions de la psychologie et de la philosophie de l'argument. Les psychologues qui s'intéressent aux arguments concentrent typiquement leurs recherches sur la compréhension de la formation et du revirement des croyances des individus. Ainsi ces théories peuvent s'employer comme des modèles de la structure des justifications des croyances, des méthodes pour diagnostiquer des croyances erronées, et des prototypes pour faciliter l'apprentissage. Les articles dans ce numéro illustrent ces trois usages.

Keywords: argumentation, fallacies, inference, learning, reasoning

\section{Introduction}

Psychologists' interest in argumentation usually stems from grappling with the problem of how people decide what to believe. For example, we sometimes need to choose which theory to adopt in scientific domains and which position to support in political controversies. Deductively valid inferences typically don't suffice to lead to beliefs about such matters; so we're forced to make do with reasoning of a less compelling kind. Our ability to come to conclusions in these uncertain contexts can vary in proficiency, especially from childhood to adulthood. Thus, psychologists have a 
stake in examining the mental skills that lead to beliefs, in evaluating these skills, and in trying to improve them.

Philosophy, particularly epistemology and philosophy of science, has exerted an important (though sometimes unacknowledged) influence on psychologists' theorizing about belief formation. Psychologists' usual strategy has been to apply philosophical models to identify the respects in which people follow or depart from correct methods for forming beliefs. For example, in determining which theory to adopt, people may attend to both the evidence supporting the theory and the theory's explanatory power, but they may confuse the roles played by these two sources of information (e.g., Kuhn, 1991). Of course, factors from outside these models may also impact beliefs. People may have difficulty searching for evidence in an unbiased way, limiting their search to facts favoring the side of an issue they initially support (Perkins, Farady, \& Bushey, 1991). They may give up their search too soon because of limitations of time and effort. They may have their search short-circuited by unconscious, automatic mental processes that throw them off course.

Theories of argument in philosophy have had a less consistent influence on psychological investigations, but their effects appear in several strands of research. One such influence comes from theories of argument structure by Fisher (1988), Toulmin (1958), and others. Such structures indicate how the parts of an argument fit together in leading to a conclusion, and they provide potential models for the way people construct and remember lines of reasoning. Comparisons between these structures and people's overt arguments can potentially identify deficiencies in thinkingmissing pieces of a chain of reasoning or misconnections in the chain. Reasoners may have an incorrect idea about the proper structure or purpose of arguments and therefore produce arguments that are incomplete or heavily biased (e.g., Baron, 1991, 1995; Wolfe \& Britt, 2008). A second influence from the philosophy of argument comes from discussions of fallacies (e.g., Hamblin, 1970; Johnson, 1987; Woods, 1988), since fallacies offer phenomena for theories of thinking to explain. Thus, fallacies like slippery-slope and argument from ignorance (Hahn \& Oaksford, 2007), circularity (Baum, Danovitch, \& Keil, 2008; Rips, 2002), and others have come under scrutiny, not necessarily as examples of poor reasoning, but as patterns of thought that deserve investigation in their own right. Third, recent psychological research has examined two-person or multi-person argumentation, especially in the classroom. Psychologists have explored these exchanges because they believe the experience of external argumentation provides a way to improve the quality of (internal) thought.

You can see all three of these ties to argumentation in the contributions to this special issue, and the following sections of this 
introduction highlight these connections. Of course, the authors also rely on prior psychological theory, for example, theories of rational cognition (Anderson, 1990), the social psychology of attitudes and persuasion (e.g., Petty \& Cacioppo, 1986), judgment and decision-making (e.g., Tversky \& Kahneman, 1974), the psychology of reasoning (e.g., Evans, Newstead, \& Byrne, 1993), and other sources. I'll note these traditions, too, but my treatment of these issues will be brief, usually limited to mentioning entry points to the relevant literature.

\section{Structural approaches to thinking}

During the 1970s and '80s, several groups of researchers in cognitive psychology and artificial intelligence proposed that people store complex information in organized memory packages. For example, Rumelhart (1975) suggested that when we read simple stories, we remember their information in mental schemas that specify the basic parts of the narrative (its setting, episodes, consequences, and so on) and their interrelations. Psychologists with an interest in educational issues adopted similar theories about students' understanding of information in domains of school subject matter, such as elementary physical and social science. Unlike most stories, however, topics in academic disciplines often have an argumentative structure that clusters around central issues, emphasizing the evidence that supports each of its sides. Textbooks may discuss, for example, alternative causes for a particular treaty or the costs and benefits of an economic intervention.

To describe the structure of this material, researchers needed a way to characterize these informal arguments. A particular concern was evaluating students' abilities to produce (or reproduce) lines of reasoning for and against specific conclusions. When students have to think about whether or not gas prices will influence car prices, whether marijuana should be legalized, why released prisoners return to crime, or whether nuclear power should be developed as an energy source, what kinds of reasoning should they provide? Traditional research in the psychology of reasoning seemed to be of little help for these purposes, since most of this work aims at describing how people handle short formal arguments, such as categorical syllogisms (see Evans, et al., 1993, for a review). Although instances of such arguments can be strung together in more extended proofs, the reasoning from educational contexts is typically non-deductive in character and multiple-sided.

To get a handle on students’ deliberations, Resnick, Voss, and their colleagues drew on theories of argumentation (e.g., Means \& Voss, 1996; Resnick, Salmon, Zeitz, Wathen, \& Holowchak, 1993; 
Voss, Blais, Means, Greene, \& Ahwesh, 1986; Voss \& Means, 1991). Fisher (1988), Toulmin (1958; Toulmin, Rieke, \& Janik, 1984), and others provided frameworks that could be used in this endeavor, and these frameworks helped researchers locate places in students' arguments where difficulties might occur. Researchers could record the students in discussion, parse the transcripts according to one of these frameworks, and count the number of reasons produced in favor of the student's own position (versus other positions), the number of counterarguments, and so on.

When students consider controversial issues, they not only need to muster reasons but also need to understand the parts these reasons play in the overall argument. According to Kuhn (1991), for example, students need to distinguish the evidence presented in favor of a theory from the explanatory apparatus internal to the theory (Kuhn, 1991). Controversy exists about the evidence/ explanation dichotomy, controversy analogous to that surrounding the observation/theory distinction. Moreover, students are rarely in a position to gather evidence for a theory about a real-world issue, especially within the confines of an experimental interview: They can't stop the experiment to go out and gather relevant data on their own. The evidence they can bring to bear is almost always hypothetical-evidence that they might be able to collect if they were in a position to do so. People's difficulty in obtaining relevant evidence may make it less surprising that they have problems separating evidence and explanation (Brem \& Rips, 2000). Two of the contributions to the special issue (Goldstein, Crowell, \& Kuhn and Barchfeld \& Sodian) attempt to examine this problem by looking at students' thinking about arguments that are presented to them rather than asking the student to construct their own arguments. Both studies suggest that the difficulties of separating evidence and explanation persist when students have the arguments at hand.

\section{Errors in thinking}

Well-known studies of decision making by Tversky and Kahneman (e.g., 1974) pointed to short-comings in people's judgments about probability. Other forms of non-deductive reasoning could also be seen as errors, including some of the tendencies mentioned earlier (failure to distinguish evidence from explanation, and "my-side bias," the tendency to rely more heavily on evidence that supports one's own position than on evidence that supports others'). So could related tendencies toward dogmatism and absolutism (Stanovich \& West, 1997) and toward over-scrutiny of others' positions (Edwards \& Smith, 1996). 
However, a proposal by Anderson (1990) suggested that a fruitful approach to cognition might be to regard mental processes as implementations of strategies that are themselves optimal, given mental and environmental constraints. In this context, what seemed to be reasoning errors could sometimes be reinterpreted as approximations to correct thinking. Oaksford, Chater, and Hahn (2008) have applied this strategy to a wide range of problems, both those that have nominally deductive solutions and those that are non-deductive. Their analysis extends to traditional reasoning fallacies, such as slippery slope, as noted earlier. In the present issue, Hahn, Harris, and Corner use the same strategy in interpreting arguments from ignorance or appeals to authority. This approach toward argumentation takes the strength of an inference to be the conditional probability of its conclusion given available evidence, where the evidence in some cases may be drawn from outside the argument itself. In the case of arguments from ignorance, for example, the strength of an argument such as "Drug $\mathrm{X}$ is safe because JAMA reported 10 studies with no side effects," depends on the strength of the evidence (the number of studies) and on the reliability of the source (JAMA).

Perhaps one could apply a similar analysis to Baron's finding (in this issue) of over-consistency in people's evaluation of a candidate's positions on distinct issues. If you like a particular candidate, then the positive weight assigned to this source may produce a correlation among your beliefs in the issues she supports. But would showing that a Bayesian model provides a good fit to these data demonstrate that this tendency is a reasonable one? Baron argues, to the contrary, that such tendencies can be due to wishful thinking or self-deception. Having decided to support Candidate $\mathrm{X}$ because of her stand on abortion, you might unconsciously increase your support for $X$ 's stance on taxation in order to maintain consistency. This could be true even if you have no reason to think abortion and taxation have implications for each other or that the candidate's expertise on one issue generalizes to the other. This question points to second. Because all the probabilities that go into a Bayesian model are subjective ones, the model does not guarantee accurate probabilities for the beliefs themselves, except under special conditions. Obeying Bayesian prescriptions doesn't insure that your subjective probabilities (e.g., $90 \%$ chance of rain today) will yield a correct appraisal of reality. If one goal of argument is the production of true beliefs, then Bayesian strategies (and their cognitive approximations) are limited in their ability to describe the correct argumentative procedure.

The Bayesian approach has advantages, especially in revealing the interactions among different types of information. However, some problems in argumentation and some problems in thinking 
seem structural in character, and it may be more informative to treat them in structural terms than in Bayesian ones. For example, question begging seems problematic precisely because of its structure, and the implications of such fallacies for thinking may be more revealingly handled by the sorts of theories mentioned in the preceding section. Or perhaps structural and Bayesian approaches can be combined in a way that merges their strengths by recruiting tools from Bayes-net proposals (Pearl, 2000; Spirtes, Glymour, \& Scheines,1993), as Hahn et al. suggest.

\section{Two-person and multi-person argumentation}

Interest in multi-person argumentation again filters into psychology because of an interest in belief fixation, especially in the context of classroom learning (see Chinn, 2006, for a review). The intuition is that if students can learn to manage their ideas in argumentative interactions with fellow students, then they should be able to internalize these strategies in a way that will improve their thinking and learning (e.g., Reznitskaya et al., 2001). The main influences from the psychology side are Vygotsky's (1978) theory of development and perhaps also Billig's (1996) theory of attitudes as reflections of the social and rhetorical context of controversial issues. Most cognitive developmental psychologists are probably wary of the idea that people can simply absorb the lessons of an external debate by experiencing it. Some internal understanding of the nature of argumentation is a likely prerequisite to profiting from external deliberations. Still, participating in classroom arguments may sometimes benefit students' learning, as may practice with software designed to enhance argument analysis (e.g., van Gelder, 2000).

In this issue, articles by Felton, Garcia-Mila, and Gilabert and by Goldstein et al. fall in this tradition, but they add some important qualifications to the notion that participating in argumentative discussions can benefit students. Goldstein et al. report that specific training in formulating arguments helped middle-school students to advance points that are sensitive to their opponents' position. However, these investigators found relatively little transfer from this training to the students' skill at evaluating the arguments of others. That is, the training produced little improvement in students' assessments of arguments they read about but didn't participate in. Along related lines, Felton et al. document the fact that students' learning from argumentative debates depends on their goals. Students who had the task of coming to an agreement with their opponent learned more about an issue than did control subjects who merely read the text and 
outlined the pros and cons. By contrast, students who had to persuade their opponent showed no advantage over the controls.

Felton et al.'s findings make the point that the purposes of arguments can affect how much students learn from them. These findings also raise questions about which purposes are appropriate in different contexts of learning. Deciding on a policy may profit from cooperative strategies in argument, as might deciding on the conduct of collaborative research. But other goals, such as evaluating research findings or selecting the best theory for a set of data, might call for different, perhaps less cooperative, approaches. Similarly, the advantages or disadvantages of a dispute might depend on whether the students have to defend their own point of view, defend a single point of view (whether their own or not), or defend (rather than being able to compromise on) a position. Perhaps members of a debate team, who have to defend each side of an issue on separate occasions, but don't have the option of agreeing with their opponents, would still arrive at a better understanding of the issue than students who defend only a single side. We should also evaluate arguments by different standards when they are addressed to different goals (Walton, 1998), and this may carry over to the kinds of learning we should expect from students who participate in these arguments.

Theories of two- or multi-person arguments (e.g., Walton \& Krabbe, 1995; van Eemeren \& Grootendorst, 1992) are relevant to this endeavor, as is related work in game theory and negotiation. But somewhat oddly, this influence has not penetrated very far into psychological or educational studies. Some work of my own (Rips, 1998) proposed combining a "syntactic" framework for two-person argument (modeled in terms of moves and counter-moves between opponents) with a "semantic" framework (determining which propositions the opponents were committed to as a result of their moves). This two-part framework produced some theorems about the conditions under which opponents will reach agreement, and it suggested experiments on how closely real arguments conform to these conditions. The experiments I did on this topic, however, all involved participants reading two-person arguments and making judgments about the commitments of the characters. No attempt was made to apply the framework to classroom (or other) settings in order to diagnose or improve student practices. Better connections between the theory of argument, its psychological ramifications, and its classroom applications are needed at this point, and perhaps this special issue will help foster these connections. 


\section{Acknowledgments:}

I'm very grateful to the authors of the articles in this issue for their insights and co-operation and to Ralph Johnson for his advice on editorial matters. And although I can't thank them by name without violating confidentiality, I do thank the referees of these articles for their very careful reading and argumentation.

\section{References}

Anderson, J. R. (1990). The adaptive character of thought. Hillsdale, NJ: Erlbaum.

Baron, J. (1991). Beliefs about thinking. In: J. F. Voss, D. N. Perkins \& J. W. Segal (Eds.), Informal reasoning and education (pp. 169-186), Cambridge, UK: Cambridge University Press.

Baron, J. (1995). Myside bias in thinking about abortion. Thinking and Reasoning 1, 221-235.

Baum, L. A., Danovitch, J. H., \& Keil, F. C. (2008). Children's sensitivity to circular explanations. Journal of Experimental Child Psychology 100, 146-155.

Billig, M. (1996). Arguing and thinking: A rhetorical approach to social psychology (New ed.). Cambridge, UK: Cambridge University Press

Brem, S. K., \& Rips, L. J. (2000). Explanation and evidence in informal argument. Cognitive Science 24, 573-604.

Chinn, C. A. (2006). Learning to argue. In: A. M. O'Donnell, C. E. Hmelo-Silver \& G. Erkens (Eds.), Collaborative learning, reasoning, and technology (pp. 355-383), Mahwah, NJ: Erlbaum.

Corner, A., Hahn, U., \& Oaksford, M. (2006). The slippery slope argument: Probability, utility and category boundary reappraisal. In: R. Sun \& N. Miyake (Eds.), Proceedings of the 28th Annual Conference of the Cognitive Science Society (pp. 1145-1151), Austin, TX: Cognitive Science Society.

Edwards, K., \& Smith, E. E. (1996). A disconfirmation bias in the evaluation of arguments. Journal of Personality and Social Psychology 71, 5-24.

Evans, J. St.B. T., Newstead, S. E., \& Byrne, R. M. J. (1993). Human reasoning: the psychology of deduction. Hove: Erlbaum.

Fisher, A. (1988). The logic of real arguments. Cambridge, UK: Cambridge University Press.

Hahn, U., \& Oaksford, M. (2007). The rationality of informal argumentation: A Bayesian approach to reasoning fallacies. Psychological Review 114, 704-732. 
Hamblin, C. L. (1970). Fallacies. London: Methuen.

Johnson, R. H. (1987). The blaze of her splendors: Suggestions about revitalizing fallacy theory. Argumentation 1, 239-253.

Kuhn, D. (1991). The skills of argument. Cambridge, UK: Cambridge University Press.

Means, M. L., \& Voss, J. F. (1996). Who reasons well? Two studies of informal reasoning among children of different grade, ability, and knowledge levels. Cognition and Instruction 14, 139-178.

Oaksford, M., Chater, N., \& Hahn, U. (2008). Human reasoning and argumentation: A probabilistic approach. In: J. E. Adler \& L. J. Rips (Eds.), Reasoning: Studies of inference and its foundations (pp. 383-413), Cambridge, UK: Cambridge University Press.

Pearl, J. (2000). Causality: models, reasoning, and inference. Cambridge, U.K.: Cambridge University Press.

Perkins, D. N., Farady, M., \& Bushey, B. (1991). Everyday reasoning and the roots of intelligence. In: J. F. Voss, D. N. Perkins \& J. W. Segal (Eds.), Informal reasoning and education (pp. 37-58), Cambridge, UK: Cambridge University Press.

Petty, R. E., \& Cacioppo, J. T. (1986). Communication and persuasion: Central and peripheral routes to attitude change. New York: Springer-Verlag.

Resnick, L. B., Salmon, M., Zeitz, C. M., Wathen, S. H., \& Holowchak, M. (1993). Reasoning in conversation. Cognition and Instruction 11, 347-364.

Reznitskaya, A., Anderson, R. C., McNurlen, B., Nguyen-Jahiel, K., Archodidou, A., \& Kim, S.-y. (2001). Influence of oral discussion on written argument. Discourse Processes 32, 155 175.

Rips, L. J. (1998). Reasoning and conversation. Psychological Review 105, 411-441.

Rips, L. J. (2002). Circular reasoning. Cognitive Science 26, 767795.

Rumelhart, D. E. (1975). Notes on a schema for stories. In: D. G. Bobrow \& A. Collins (Eds.), Representation and understanding: Studies in cognitive science (pp. 211-236), New York: Academic Press.

Spirtes, P., Glymour, C. N., \& Scheines, R. (1993). Causation, prediction, and search. New York: Springer-Verlag.

Stanovich, K. E., \& West, R. F. (1997). Reasoning independently of prior belief and individual differences in actively openminded thinking. Journal of Educational Psychology 89, 342357. 
Toulmin, S., Rieke, R., \& Janik, A. (1984). An introduction to reasoning (2nd ed.). New York: Macmillan.

Toulmin, S. E. (1958). The uses of argument. Cambridge UK: University Press.

Tversky, A., \& Kahneman, D. (1974). Judgment and uncertainty: Heuristics and biases. Science 185, 1124-1131.

van Eemeren, F. H., \& Grootendorst, R. (1992). Argumentation, communication, and fallacies: A pragma-dialectical perspective. Hillsdale, NJ: Erlbaum.

van Gelder, T. J. (2000). Learning to reason: A REASON!-able approach. In: C. Davis, T. J. van Gelder, \& R. Wales (Eds.), Cognitive Science in Australia, 2000: Proceedings of the fifth Australasian Cognitive Society conference, Adelaide.

Voss, J. F., Blais, J., Means, M. L., Greene, T. R., \& Ahwesh, E. (1986). Informal reasoning and subject matter knowledge in the solving of economics problems by naive and novice individuals. Cognition and Instruction 3, 269-302.

Voss, J. F., Means, M. L., \& (1991). Learning to reason via instruction in argumentation. Learning and Instruction 1, 337350.

Vygotsky, L. S. (1978). Mind in society: the development of higher psychological processes. Cambridge, MA: Harvard University Press.

Walton, D. (1998). The new dialectic: Conversational contexts of argument. Toronto: University of Toronto Press.

Walton, D. N., \& Krabbe, E. C. W. (1995). Commitment in dialogue: Basic concepts of interpersonal reasoning. Albany, NY: State University of New York Press.

Wolfe, C. R., \& Britt, M. A. (2008). The locus of the myside bias in written argumentation. Thinking and Reasoning 14, 1-27.

Woods, J. (1988). Buttercups, GNP's, and quarks: Are fallacies theoretical entities? Informal Logic 10, 67-76. 